\title{
MULTILEVEL ANALYSIS OF FACTORS PREDICTING SELF EFFICACY IN COMPUTER PROGRAMMING
}

\author{
${ }^{1}$ Owolabi J. And ${ }^{2}$ Adegoke B.A \\ ${ }^{1}$ Federal College of Education (Technical), Akoka, Lagos, \\ Nigeria \\ ${ }^{2}$ University of Ibadan, Ibadan, Oyo State, Nigeria
}

\begin{abstract}
This study used multilevel analysis to determine the predictive value of selected intrinsic factors (gender, computer ownership, mathematics background and computer experience) and institutional type (an extrinsic factor) on undergraduates' Self Efficacy in Java Computer Programming (SEiJCP) in SouthWest, Nigeria. The study adopted a correlational design. Purposive Sampling was used to select 254 computer science undergraduates from four universities (three federal-owned and one state-owned) in south-west, Nigeria. Three research questions were answered. Two research instruments namely, Computer experience scale $(r=0.84)$ and Java Programming Self Efficacy Scale (JPSES, $r=0.96)$ were used to collect data. Data were analysed using descriptive statistics, and null and linear growth model (LGM) procedures. The intercorrelation coefficients among the extrinsic factor, intrinsic factors and SEiJCP were moderate. Null model shows that the variations in SEiJCP accounted for by insitutional level differences was 99.0\%. The fixed part of the LGM of intrinsic factors showed that only mathematical backgroung contributed significantly $(p<0.05)$ to the prediction of SEiJCP. The random part of the LGM showed no significant contributions of the interactions of the intrinsic factors, to the prediction of SEiJCP. About $60.0 \%$ of the student level variation in SEiJCP is explained by the differences in intrinsic factors. The institution - level variable had large predictive value on programming self efficacy. Computer science departments should increase the number of mathematics courses in their curriculum.
\end{abstract}

\section{KEYWORDS}

Multilevel analysis, Self Efficacy, Java Computer Programming, Intrinsic factors, Extrinsic factors

\section{INTRODUCTION}

Self-efficacy is an important psychological construct which requires attention in research as it influences (i) the choice of activities that an individual takes part in; (ii) the amount of effort they will expend in performing a task and (iii) how long they will persevere in the face of stressful situations in completing that task [1]. Social cognitive theory posits that a strong sense of selfefficacy leads individuals to undertake challenging tasks, expend greater effort in accomplishing a given task, persist longer in the face of adversaries [2].

Of the various factors that affects individual's willingness and ability to interact with computers examined in past research, computer self-efficacy (CSE) has been identified as a key determinant of computer related ability (including programming) and use of computer [3].

Research findings show that higher levels of perceived self-efficacy correlate to greater motivational efforts and perseverance [4]. Self efficacy theory, according to has emerged as an

DOI : $10.5121 /$ ijite.2014.3203 
important means of understanding and predicting a person's performance [5]. According to [6], higher levels of computer self-efficacy correspond to greater achievement of computer competence. Given the research evidence on the influence of self-efficacy outlined above, it is reasonable to think that high self-efficacy in computer programming might play an important role in learning and writing programs and consequently producing competent and effective programmers in our nation. There is therefore the need to study factors that influence self efficacy itself.

Perceived self-efficacy in programming was seen to affect performance in programming courses [7]. There seems to be no research report yet on factors predicting self efficacy in computer programming in Nigeria. No doubt, computer undergradutes' self efficacy are functions of many factors ranging from intrinsic to extrinsic factors. The intrinsic factors are those in which the student himself or herself has a significant input or part of the real nature of the student such as his or her gender, computer experience, locus of control, mathematics background, computer ownership and number of programming courses before entering JAVA class; while the extrinsic factors are those in which the student has little or no significant input, or not part of real nature of the student such as the type of institution which he or she attends.

Studies on the relationship between computer experience and computer programming selfefficacy and achievement are very rare. In a study of factors related to JAVA programming self efficacy among engineering students in Turkey it was discovered that the number of years of computer experience had a significant linear contribution to JAVA programming self efficacy scores [5]. However, in a similar study among engineering students in a University in south- west, Nigeria it was found that the number of years of experience in programming did not significantly predict JAVA programming self-efficacy scores [8].

In research, relationship between gender and computer self-efficacy has been of regular interest, possibly because the computer was seen as a skill area for the male folks. So far, findings on gender influence on computer self-efficacy are mixed. [6] found no gender differences in computer self-efficacy. [9] observed gender differences in perceived self-efficacy regarding completion of complex tasks in both word processing and spreadsheet software (with males having higher CSE scores). In the same study, no gender differences were found in self-efficacy regarding simple computer tasks. In another study of factors related to self efficacy for Java programming among engineering students in Turkey males had higher programming self-efficacy [5].

Mathematics achievement has also been identified in literature as a factor that affects computer programming $[10,11,12]$. A possible reason for this could be because mathematics problem solving and programming require similar skills and ability to succeed. Mathematics ability, measured as achievement is however different from mathematics background. The number of mathematics courses taken by the respondents before the study was used as the mathematics background.

The relationship between computer ownership and computer self-efficacy has never been found to be consistent in previous findings. [13] in in a study found that owning a computer is significantly correlated with computer self efficacy. [9]found that students who have access to their own computer cooperated more in front of the computer than any other group. However, owning a computer was not found to be a significant predictor of computer self-efficacy [4]. 
In this study, the data is multilevel in nature, because respondents ( the students) are nested within their institutions. When this happens, one option will be to carry out institutional analysis by aggregating students' characteristics over their institutions. There is no doubt that in the process, all individual information is lost. Most times, within group variation which accounts for most of the total variation in the outcome is lost. The loss of individual information therefore can have an adverse effect on the analysis and also lead to distortion of relationships between variables. Another option is to disaggregate the data by assigning institutional data to individual students. By this, the assumption of independent observation would no longer hold. In hierarchical data, individuals in the same group are also likely to be more similar than individuals in the different groups. Therefore the variations in outcome may be due to difference between groups and to individual difference within a group.

Researchers have shown little or no interest in identifying variables that are likely to influence undergraduates' computer programming self-efficacy. Also multilevel data collected for this study is best analysed using multilevel data analysis approach. This study therefore sought to use multilevel analysis to determine the extent to which selected students' intrinsic factors (gender, computer ownership, mathematics background and computer experience) and type of institutions can predict undergraduates' self efficacy in programming.

\subsection{Research Questions}

1. The study sought answers to the following research questions.

2. What type of relationship exist among students' gender, computer ownership, mathematics background, computer experience, institution type and SEiJCP ?

3. How much of the total variance in SEiJCP of computer undergraduates is accounted for by institution-level and student-level differences?

4. How much of the student-level variance in SEiJCP of computer undergraduates is associated with gender, computer ownership, mathematics background and computer experience?

\section{METHODOLOGY}

\subsection{Participants}

This study adopted purposive sampling for the selection of participants' universities and levels of study. The Universities of respondents were selected based on the following criteria: (i)The university is owned by federal or state government, (ii) There is a computer science department where computer professionals are being trained, (iii) Java programming language is taught in the computer science department of the university. In all, at the time of the study, five (5) Universities within the South - West, Nigeria satisfied the three criteria above. One of the five was used for the trial testing, validation and reliability of the instruments before the main study. The remaining four (4) Universities were used for the real study. The computer undergraduates in the four Universities, who had been taught JAVA programming language and were willing to participate in the study formed the sample for this study. 
The levels of the participants for the study were selected based on the following criterium (i) the students at that level had been taught Java in the previous or current semester, For those who are currently on it, they had covered enough ground to enable them answer the questions set. Different levels based on the programmes and peculiarities of each Universities were therefore used. Each participant used was selected based on the following criteria: (i.) he / she is a full time student in the department of computer science in any of the chosen Universities, (ii.) he / she had been taught Java programming Language, (iii.) he / she is available at the time of data collection, (iv.) he / she is patient and willing to participate in the study. All the students in the selected levels that were available were served the questionnaire. Some of the questionnaires were however not returned. Some that were returned were not properly filled. After scrutinisng the returned questionnaires, those that were properly filled were used for the study. A total of 254 questionnaires that were properly filled were used for the study.

\subsection{Variables and Measurement Instruments}

The variables involved in the study are as follows:

Predictor variables: (i) Gender (ii) Computer Ownership (iii) Mathematics Background, (iv) Computer Experiences (v) Type of institution

Criterion variable: Self Efficacy in Java Computer Programming (SEiJCP).

Two instruments were used in the study. They were: (i) Student background questionnaire (SBQ) and (ii) JAVA Programming Self Efficacy Scale (JPSES).

\subsubsection{Student background questionnaire (SBQ)}

Student background questionnaire (SBQ) was used to obtain data on the biography of undergraduate computer students. Specifically, data on the following variables were collected with the use of the SBQ: (i) Gender (ii) Computer Ownership (iii) Mathematics Background (iv) Computer Experience and (v)student's institution. Computer experience is multidimensional. Different aspects of this variable is therefore highlighted in this work.Specifically the following 10 areas of computing were highlighted:Word Processing, Spread Sheet, Data Base, Presentation Software, Operating System Software, Computer Graphics, Computer Games, Internet, Statistical Package, Programming. The participants were given instruction to rate their experiences in the different areas of computing using a scale of 1 to 10. Maximum score obtainable is 100 while the minimum score is 10 . The scale was also trial - tested on computer undergraduates (a group parallel to the subjects of the main study). The aim was to establish its reliability among computer undergraduates in South -West, Nigeria. The reliability coefficient using Cronbach Alpha was found to be 0.84 . It was therefore found to be very reliable and fit for the study. For Mathematics background, the study considered the number of mathematics courses taken in the University before entering the Java class. 


\subsubsection{Java Programming Self Efficacy Scale (JPSES)}

The Java Programming Self Efficacy Scale (JPSES) is the adapted version of the C++ programming self Efficacy scale of [7]. It was designed by [5]. It consisted of 32 items bothering on respondents' understanding of certain concepts in the language, possession and the ability to display certain skills as well as the will to persevere when writing the programs in JAVA. The participants were given instructions to rate their confidence in understanding and doing the JAVA programming related tasks using a scale of 1 (Not confident at all) to 7 (Absolutely confident). Maximum score obtainable is 224, while the minimum score is 32. [5] administered it to Engineering undergraduates in Turkey who had been instructed in JAVA programming. The reliability was found to be 0.99 . The same instrument was trial tested on Computer undergraduates on a group parallel to the subjects of the main study who had also been instructed on JAVA programming. The aim was to establish its reliability among Computer undergraduates in South-West, Nigeria. The reliabilty coefficient was found to be 0.96 . It was found to be very reliable and fit to be used. The instrument was therefore adopted for the study.

\subsubsection{Data Analysis Procedure}

The data collected was analysed using the Statistical Package for Social Sciences (SPSS) version 17.0 and Linear Structural Relations (LISREL) version 8.80 (Jöreskog \& Sörbom, 2006). The following statistical procedures were used: Mean, Standard Deviation, Pearson Product Moment Correlation (PPMC) Coefficient (Research Questions 1) and Multilevel Analysis using LISREL (Research Questions 2 and 3).

\section{RESULT AND DISCUSSION}

Table 1 presents the intercorrelation matrix of the correlation coefficients of the selected student background variable (gender, computer ownership, mathematics background and computer experience), type of institution and SEiJCP .

Table 1: Inter correlation Matrix of Intrinsic and Extrinsic factors and SEiJCP.

\begin{tabular}{|l|l|l|l|l|l|l|}
\hline \multicolumn{1}{|c|}{ Var } & GD & MB & CE & CO & INST & SEiJCP \\
\hline Gd & 1.000 & & & & & \\
\hline MB & 0.091 & 1.000 & & & & \\
\hline CE & $0.226^{*}$ & $0.232^{*}$ & 1.000 & & & \\
\hline CO & 0.009 & $-0.225^{*}$ & 0.024 & 1.000 & & \\
\hline INST & 0.010 & $.481^{*}$ & $.214^{*}$ & $0.260^{*}$ & 1.000 & \\
\hline SEiJCP & 0.104 & $0.270^{*}$ & $0.468^{*}$ & 0.081 & $0.431^{*}$ & 1.000 \\
\hline Mean & 1.30 & 4.58 & 53.07 & 1.17 & 1.24 & 139.55 \\
\hline SD & 0.46 & 2.40 & 14.98 & 0.38 & 0.26 & 44.15 \\
\hline
\end{tabular}

Note: $G d=$ Gender; $C O=$ Computer Ownership; $M B=$ Mathematics Bachground; $C E=$ Computer

Experience; JPSES = JAVA programming Self Efficacy Scores; INS Institution-level differences.. * $p<.05$ 
Table 1 above showed that the main criterion which is SEiJCP, has positive and significant relationship with mathematics background $(\mathrm{r}=0.270, \mathrm{p}<0.05)$ and computer experience $(\mathrm{r}=$ $0.468, \mathrm{p}<0.05)$, therefore as the number of mathematics courses taken and the computer experiences increase, there is the tendency for increase in programming self efficacy among computer undergraduates. The relationship between institution-level differences and mathematics background $(r=0.481, p<0.05)$, computer owneship $(r=0.260, p<0.05)$, and computer experience $(\mathrm{r}=0.214, \mathrm{p}<0.05)$ are statistically significant.

This finding of a significant relationship between computer experience and SEiJCP is in agreement with the findings of [14]. [8] however found out that number of years of programming experience and SEiJCP were not significantly related. The inconsistency in the finding of this study and that of [8] might have occured because Jegede's respondents were non computer majors (Engineering students) while this study used computer majors. For a non - computer major, longer years of programming experience may not be a good predictor of skill acquisition or self confidence in programming. Where there is no consistency in computer usage, years of computer usage might not be a good measure of computer experience. Also, consistency in utilisation of computer should be better among computer majors compared to their non computer major counterparts.

Mathematics background in this study was also found to have a relationship which is positive and significant with Java programming self efficacy. This finding could be because mathematics problem solving and programming require similar skills and ability to succeed. According to [10], problem solving strategies employed in a traditional college mathematics course are essentially the same in a first course in computer programming.

To answer research question two, a multilevel analysis was conducted with ordinary least square option of LISREL. The model used is known as null model in that only the intercept of institution-level (macro level) was entered. That is, the focus was on variance decomposition of SEiJCP on the basis of student-level differences (level 1) and institution-level differences (level 2).

Statistically, the null modelling for variance decomposition of self efficacy is given by SEiJCP $_{i j}=\beta_{0}+\mathrm{u}_{0 \mathrm{i}}+\mathrm{e}_{\mathrm{ij}}$; Where SEiJCP ${ }_{\mathrm{ij}}$ represents score “ $\mathrm{j}$ " for student “i”; $\beta_{0}$ represents the intercept of the fixed part of the model and $\mathrm{u}_{\mathrm{oi}}$ represents the random variation in intercepts at level -2 of the model and eij denotes the random variation at level -1 of the model. Tables 2 and 3 present the fixed part of the model and random part of the model.

Table 2: Fixed Part of the Null Model for SEiJCP

\begin{tabular}{|l|l|l|l|l|l|}
\hline Co-efficients & BETA-HAT & STD.ERR & Z - VALUE & PROB & MODEL-FIT \\
\hline Intercept & 9.15 & 6.00 & 1.52 & 0.13 & 2495.86 \\
\hline
\end{tabular}

The results in Table 2 indicate that the intercept of the fixed part of the model is 9.15 and it is not statistically significant $(\mathrm{p}>.05)$. 
International Journal on Integrating Technology in Education (IJITE) Vol.3, No.2, June 2014

Table 3: Random Part of the Null Model for SEiJCP

\begin{tabular}{|l|l|l|l|l|}
\hline LEVEL & THAU - HAT & STD.ERROR & Z - VALUE & PROB \\
\hline $\begin{array}{l}\text { LEVEL2 } \\
\text { Intercept / intercept }\end{array}$ & 4.01 & 15.40 & 0.26 & 0.795 \\
\hline $\begin{array}{l}\text { LEVEL 1 } \\
\text { Intercept / intercept }\end{array}$ & 301.37 & 0.00 & 0.00 & 0.000 \\
\hline
\end{tabular}

We estimate the total variance in Java programming Self efficacy by using equation 1 below:

$\frac{\Phi_{1}}{\Phi_{2}+\Phi_{1}}=$ Total Variance

Where $\Phi_{2}$ represent between group variability (Variance of level-2) and $\Phi_{1}$ represent within group variability (variance of level-1).

From table $3, \Phi_{2}=4.01$ and $\Phi_{1}=301.37$

$\therefore$ Total variance in Programming self efficacy $=\frac{\phi_{1}}{\Phi_{2}+\Phi_{1}}$

This is given as $\frac{301.37}{4.01+301.37}=\frac{301.57}{305.58}=0.99$

Therefore the total variance in SEiJCP accounted for by institution-level differences is 0.99 . This result indicates that about $99.0 \%$ of the total variation in programming self efficacy is explained by the differences in institution.

To obtain total variance accounted for by student-level differences (level 1) we use the formula. Micro level differences for null model $=1-$ Total variance at level 2

This gives $1-0.99=0.01$

Therefore total variance accounted for by student-level differences is about $1.0 \%$.

The results of this study indicated that $99.0 \%$ of the total variation in SEiJCP was accounted for by institution-level differences. The remaining $1.0 \%$ was accounted for by the student-level differences. Institutional - level differences contributed more to variation in SEiJCP in this study compared to student level contributions. It then follows that institution - level differences play a significant role in determining the confidence computer undergraduates have in their ability to program. This claim could be supported by the finding of [15] in a study carried out to determine the extent to which teacher self efficacy and students mathematics self efficacy could enhance secondary school students' achievement. In that study, it was found that teachers frequent use of mathematics homework and level of interest and enjoyment of mathematics as well as their ability and competence in teaching mathematics played a key role in promoting students mathematics self efficacy. To boost students' SEiJCP, students should not only be the focus, the institutions must also create an enabling environment.

To answer research question three, a multilevel analysis was conducted with ordinary least square option of LISREL. The model used is known as model 1 in that explanatory variables of student- 
level differences plus the intercept of institution-level (macro level) were entered. That is, the focus was on linear growth model with random intercepts and their slopes

Statistically, the null modelling for variance decomposition of SEiJCP is given by

$\operatorname{SEiJCP}_{\mathrm{ij}}=\beta_{0}+\beta_{1} \mathrm{XGd}_{\mathrm{ij}}+\mathrm{u}_{0 \mathrm{i}}+\mathrm{u}_{\mathrm{ij}} \mathrm{XGd}_{\mathrm{ij}}+\beta_{2} \mathrm{XCO}_{\mathrm{ij}}+\mathrm{u}_{0 \mathrm{i}}+\mathrm{u}_{\mathrm{ij}} \mathrm{XCO}_{\mathrm{ij}}+\beta_{3} X \mathrm{CE}_{\mathrm{ij}}+\mathrm{u}_{0 \mathrm{i}}+\mathrm{u}_{\mathrm{ij}} \mathrm{XCE}_{\mathrm{ij}}$ $+\beta_{4} X \mathrm{XB}_{\mathrm{ij}}+\mathrm{u}_{0 \mathrm{i}}+\mathrm{u}_{\mathrm{ij}} \mathrm{XMB}_{\mathrm{ij}} \mathrm{e}_{\mathrm{ij}}$

Where SEiJCP ${ }_{\mathrm{ij}}$ represents score " $\mathrm{j}$ " for student "i"; $\beta_{0}$ represents the intercept of the fixed part of the model and $u_{\mathrm{oi}}$ represents the random variation in intercepts at level -2 of the model and eij denotes the random variation at level -1 of the model, $\mathrm{u}_{\mathrm{ij}}$ represents the random variation in slopes for each of the intrinsic factors. Tables 4 and 5 present the fixed part of the model and random part of the model.

Table 4: Fixed Part of the Linear Growth Model 1 of Intrinsic factors

\begin{tabular}{lcccc}
\hline COEFFICIENTS & BETA-HAT & STD.ERR & Z-VALUE & PR > |Z $\mid$ \\
\hline Intcept & 7.81 & 8.34 & 0.94 & 0.349 \\
Gender & 2.43 & 2.58 & 0.94 & 0.347 \\
Owncomp & 1.57 & 3.59 & -0.44 & 0.661 \\
Mathematics bgd & 1.34 & 0.64 & 2.10 & 0.040 \\
COMPEXP & -0.02 & 0.09 & -0.18 & 0.856
\end{tabular}

DEVIANCE $=-2 *$ LOG $($ LIKELIHOOD $)=2183.65$

NUMBER OF FREE PARAMETERS $=21$

Table 4 showed that out of the four student related variables, only mathematics background significantly contributed to the prediction model, that is undergraduates SEiJCP. None of the other variables contributed significantly to the prediction model 1 
International Journal on Integrating Technology in Education (IJITE) Vol.3, No.2, June 2014

Table 5: Random Part of the Linear Growth Model 1 of Intrinsic Factor

\begin{tabular}{|c|c|c|c|c|}
\hline LEVEL 2 & TAU-HAT & STD.ERR. & Z-VALUE & $\mathrm{PR}>|\mathrm{Z}|$ \\
\hline Intcept /intcept & 0.00 & 0.00 & 0.00 & 0.000 \\
\hline Gender /intcept & 0.00 & 0.00 & 0.00 & 0.000 \\
\hline Gender /gender & 5.77 & 124.55 & 0.05 & 0.960 \\
\hline owncomp /intcept & -14.53 & 211.36 & -0.07 & 0.945 \\
\hline owncomp /gender & 24.50 & 107.50 & 0.23 & 0.820 \\
\hline owncomp /owncomp & -3.59 & 292.16 & -0.01 & 0.990 \\
\hline Mathbgd/intcept & 48.85 & 53.25 & 0.92 & 0.360 \\
\hline Mathbgd/gender & -4.98 & 19.09 & -0.26 & 0.790 \\
\hline Mathbgd /owncomp & 2.37 & 28.40 & 0.08 & 0.930 \\
\hline Mathbgd / Mathbgd & -6.22 & 7.46 & -0.83 & 0.933 \\
\hline COMPEXP/intcept & 0.28 & 7.80 & 0.03 & 0.971 \\
\hline COMPEXP/gender & -0.53 & 2.16 & -0.25 & 0.804 \\
\hline COMPEXP /owncomp & -0.38 & 3.77 & -0.10 & 0.921 \\
\hline COMPEXP /Maths bgd & 0.06 & 0.65 & 0.09 & 0.929 \\
\hline COMPEXP/COMPEXP & 0.01 & 0.11 & 0.08 & 0.938 \\
\hline LEVEL 1 & TAU-HAT & STD.ERR. & Z-VALUE & $\mathbf{P R}>|\mathbf{Z}|$ \\
\hline intcept /intcept & 15.25 & 16.55 & 0.92 & 0.36 \\
\hline
\end{tabular}

We estimate the student-level (student background variables) variance in SEiJCP by using equation 1

$\frac{\Phi_{1}}{\Phi_{2}+\Phi_{1}}=$ Total Variance

Where $\Phi_{2}$ represent between group variability (Variance of level-2) and $\Phi_{1}$ represent within group variability (variance of level-1).

From table $4.4, \Phi_{2}=15.25$ and $\Phi_{1}=23.08$ 
$\therefore$ Total variance in Programming self efficacy $=\frac{\Phi_{1}}{\phi_{2}+\phi_{1}}$

This is given as $\frac{23.08}{15.25+23.08}=\frac{23.08}{38.33}=0.60$

Therefore the total variance in SEiJCP accounted for by student-level differences is 0.60 . This result indicates that about $60.0 \%$ of the student-level variation in SEiJCP is explained by the differences in intrinsic factors under study. However, none of the interactions contributed significantly to the observed variance in computer programming self efficacy.

Computer experience in this study did not contribute significantly to the variation in SEiJCP. This finding contradicts that of [5]. In a study of factors related to Java programming self efficacy among engineering students in Turkey they found that the number of years of computer experience had a significant linear contribution to Java programming self-efficacy scores. The non-significance in the contribution of computer experience to variation in self efficacy scores might be due to the measurement scale used for computer experience in this study where students rated their experiences in 10 areas of computing (one of which is programming) on a 7-likert scale.

\section{CONCLUSION AND RECOMMENDATION}

Computer experience in this study did not contribute significantly to the variation in SEiJCP. This therefore suggests that their experiences were more pronounced in other areas of computing than programming. It is therefore suggested that computer undergraduates are made to take more programming courses and given more tasks in programming in order to engage them more in programming than other computer related activities that are not related to their core tasks as computer majors.

\section{FUTURE WORK TO BE DONE}

This study was limited to government-owned universities in south-western Nigeria. There is the need to replicate the study in other geo-political zones in the country as well as in private universities in the country.

\section{REFERENCES}

[1] Bandura, A. (1977). Self Efficacy: Towards a Unifying Theory of behaviour. PsychologicalReview, 84(2),191-215. Retrieved from the World Wide web:http//www.ncbi.nih.gov/pubmed/847064.

[2] Bandura, A. (2006). Adolescent Development from an Agentic Perspective. In F. Pajares and T. Urdan (Eds.). Self Efficacy beliefs of Adolescents (pp. 1-43). Greenwich, Connecticut: Information Age publishing.

[3] Hasan, B. (2003). The Influence of Specific Computer Experiences on Computer Self Efficacy Beliefs.Computers in Human Behaviours 19, 443-450.

[4] Cassidy, S and Eachus, P. (2002). Developing the Computer User Self-Efficacy (CSUE) Scale: Investigating the Relationship between Computer Self-Efficacy, Gender and Experience with Computers.Educational Computing Research, 26(2), 133-153. 
[5] Askar, P. \& Davenport, D.(2009). An investigation of factors related to self-efficacy for Java Programming Among Engineering Students. Turkish Online Journal of Education Technology 8(1)

[6] Jegede P.O.(2007). Factors in computer Self-Efficacy among South-Western Nigeria College of Education. Teachers Journal of Psychology in Africa 17(1).

[7] Wiedenbeck, S. \& Ramalingam, V. (2005). Factors affecting the success of non-majors in learning to program.Proceedings of the first International Workshop of Computing Education Research, Seatle, 13-24.

[8] Jegede P.O. (2009) . Predictors of JAVA Programming self-Efficacy among engineering students in NigeriaUniversity. International Journal of Computer Science and information security (IJCSIS), available at http:/site.google.com/site/ijcsis/.

[9] Busch, T. (1995). Gender Differences in Self Efficacy and Attitudes towards Computers. Journal of Educational Computing Research, 12, 147-158.

[10] Harkins, R.J. (2008). The design and implementation of a first course in computer programming forcomputing majors, Non-majors and industry professionals within a liberal Education frame work. Informationsystem Educational Journal 6(60).

[11]Wilson, B. C (2002). A study of Factors Promoting Success in Computer Science including Gende Differences. Computer Science Education, 12, No 1 - 12, pp 141 - 164.

[12]Byrne, P., \& Lyons, G. (2001). The Effect of Student Attributes on Success in Programming. ITiCSE:Proceedings of the 6th Annual Conference on Innovation and Technology in Computer Science EducationACM Press, NY, 49-52

[13] Houle, C. (1996). The Design of Education 2nd ed. San Francisco: Jossey-Bass, 173-235.

[14] Taylor, H. \& Mounfield, L.(1989). Exploration of the Relationship between Prior Computing Experience and Gender on Success in College Computer Science. Journal of Educational Computing Research, 11(4), 291-306.

[15] Gisemba, B.J. (2011). The role of teacher characteristics and practice on upper secondary school students'mathematics self efficacy in Nyanza Pronvice of Kenya: a multilevel analysis. International Journal of science and mathematics education 9(4), 817 - 842.

\section{AUTHORS}

Josiah Owolabi is currently a Principal Lecturer and the Head of Mathematics/Statistics Department at the Federal College of Education(Technical),Akoka,Lagos,Nigeria. He holdsa B.Sc(Ed)and M.Sc in Mathematics.He is currently a research student at the Institute of Education, University of Ibadan, Nigeria.His previous work experiencebeforethe presentappointmentincludes teaching Mathematics, Further Mathematics and Computer in a secondary School.Josiah has about 20 publications in local andinternational Journals. He hadalsoauthored/co- authoredthreetextbooksinMathematicsand one in Computer Studies.Hisresearchinterestsare: Mathematics and Computer

Benson AdesinaAdegoke PhD holds B.Ed Physics/Education, M.Ed and PhD degrees in Educational Evaluation of the University of Ibadan. He had taught Physics and Mathematics for about 19years before he joined the Institute of Education,University of Ibadan as a Research Fellow. He is currently a Senior Research Fellow in the Institute of Education, University of Ibadan, Nigeria. He teaches research and statistical methods to higher degree students at the Institute of Education University of Ibadan. Benson has close to 30 publications in local and international journals. He has also authored two textbooks

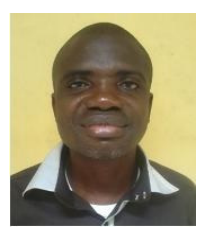
on statistics and statistical analysis. He has chapter contributions in four textbooks and was involved in the writing of 2 technical reports. Presently, his research focus is on "Improving Achievement Test Items' Construction - Emphasis on Comparing the Item Response Theory and Classical Response Theory Frameworks". 